\title{
Cattle Grub Management ${ }^{1}$
}

\author{
P. E. Kaufman and E. N. I. Weeks ${ }^{2}$
}

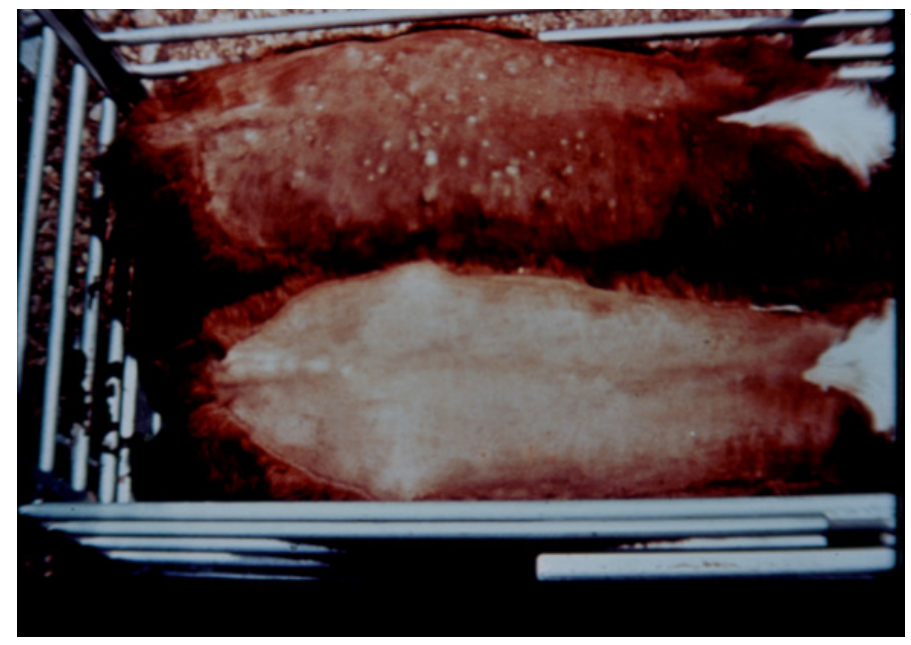

Figure 1. Cattle grub infestation. Many warbles are apparent along the backline of the top animal. The animal below was treated and has no warble damage.. Credits: P. Scholl, USDA/Ag. Canada.

Immature warble flies, or cattle grubs, infest and harm livestock throughout the world (Fig. 1). Warble flies also are known as "heel flies" because they cause cattle to kick at themselves, and "gad flies" because they cause cattle to "gad about"-or run around-in an attempt to evade the flies. Two species of cattle grubs occur in the U.S.A., Hypoderma lineatum, the common cattle grub, and Hypoderma bovis, the northern cattle grub. The common cattle grub is found in Florida and is distributed throughout the Americas from northern Mexico to northern Canada. The northern cattle grub is more limited in distribution, and is mainly found north of a line running across the country from northern California through Kansas to the Carolinas. Historically, populations of the northern cattle grub have been reported in central Florida on cattle shipped in from more northern states. Infestations of native cattle with the northern cattle grub suggest that the insect is now an established pest in Florida.

The adult cattle grubs or warble flies are large, hairy, beelike flies (Fig. 2). The adult of the northern cattle grub is the larger of the two species, averaging $15 \mathrm{~mm}$ in length, and is otherwise known as the "larger warble fly." The adult of the common cattle grub, or the "lesser warble fly," is smaller, averaging $13 \mathrm{~mm}$ in length. The adult northern cattle grub is more bee-like than the lesser warble fly, with a black and yellow striped hair pattern on the abdomen. The common cattle grub adult abdomen has a stripe of light yellow hairs, then a band of darker hair and a stripe of yellow hair on the tip.
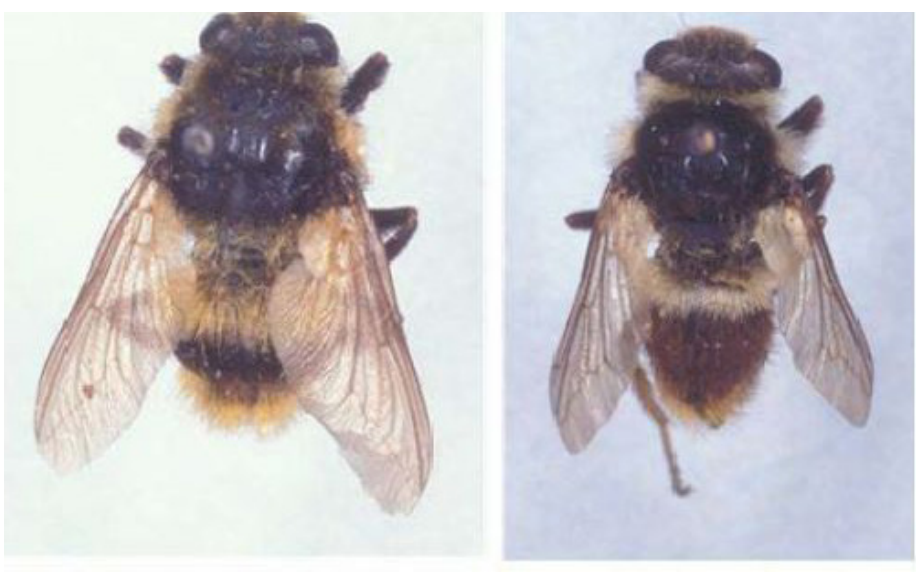

Figure 2. Warble flies, adult northern cattle grub on the left and common cattle grub on the right. Photo credits:

Credits: Lyle Buss, University of Florida.

1. This document is ENY-290, one of a series of the Entomology and Nematology Department, Florida Cooperative Extension Service, Institute of Food and Agricultural Sciences, University of Florida. Original publication date March 2013. Visit the EDIS website at http://edis.ifas.ufl.edu.

2. P. E. Kaufman, associate professor/Extension entomologist; and E. N. I. Weeks, assistant research scientist; Entomology and Nematology Department, Cooperative Extension Service, Institute of Food and Agricultural Sciences, University of Florida, Gainesville, FL 32611. 


\section{Life Cycle}

The life cycles of the common and northern cattle grub are similar (Fig. 3), differing only in egg laying behavior and the region of the body to which the larva migrates. Although both species lay their eggs on the hair of cattle, the fly behavior as well as the position and number of eggs laid differ.

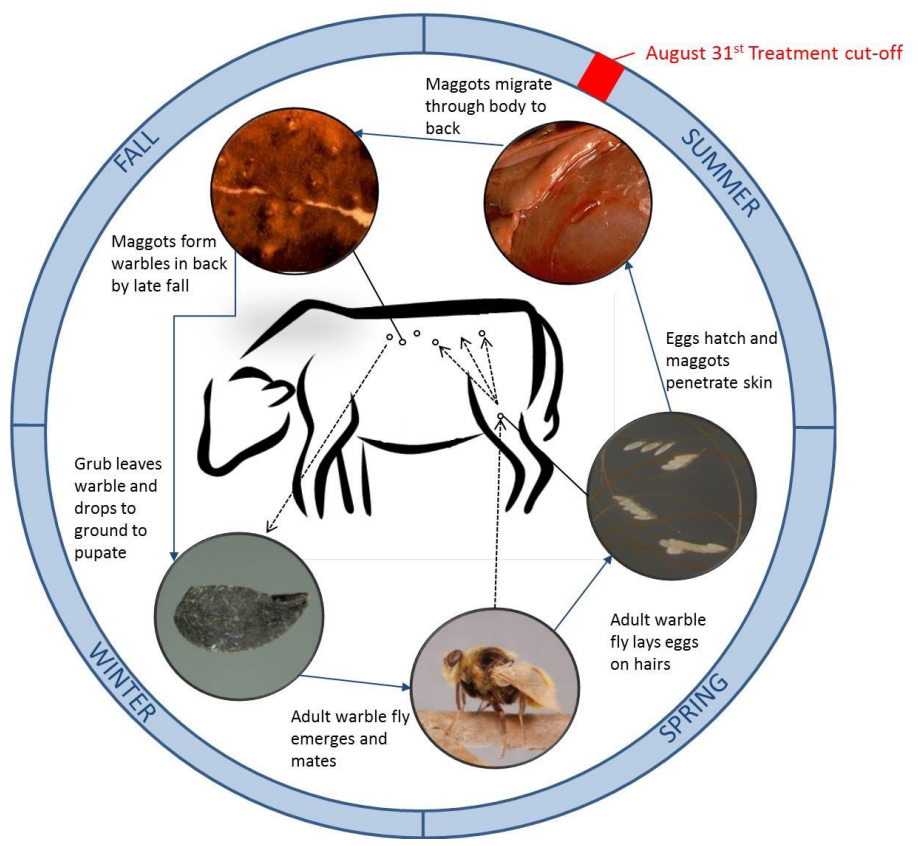

Figure 3. Cattle grub life cycle.

Credits: Illustration by E. N. I. Weeks, University of Florida. Photos by L. Buss, University of Florida and J. Weintraub, Ag. Canada (maggot stage photos). Note that the August 31st treatment cut-off stands for Florida only.

In Florida the adults of both cattle grub species are active, and the eggs are laid in the spring (February to May).

Adult females of the common cattle grub lay their eggs on lower regions of a cow's body while the animal is standing or resting. The fly lands close by and then walks onto the animal, raising little alarm. Once on the animal, the fly will lay between five and 15 eggs on a single hair and around 500 eggs on one animal (Fig.4).
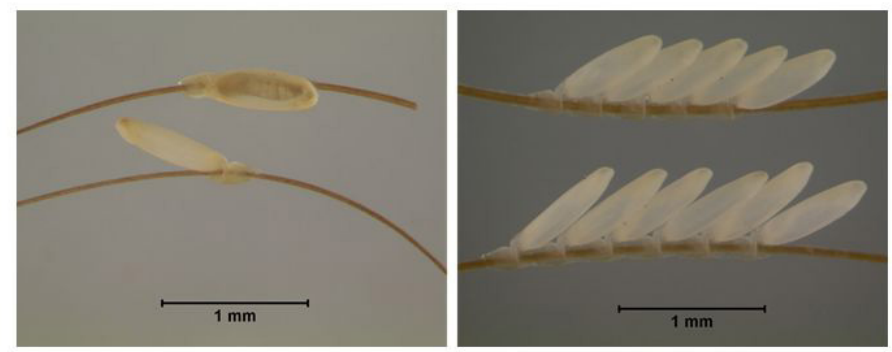

Figure 4. Warble fly eggs. Northern cattle grub eggs laid singly on the left and common cattle grub eggs laid in clusters on the right. Credits: Lyle Buss, University of Florida.
The adult northern cattle grub lays its eggs in the same areas, such as the legs and belly, but this species lays its eggs individually, one per hair, and often on non-resting hosts (Fig.4). Unlike the adults of the common cattle grub, the females of the northern cattle grub persistently pursue fleeing animals, laying eggs while the animal is running. Although the laying of the eggs is painless for the cattle, the fast-moving flies with their bee-like coloration and buzzing sounds cause panic and the cattle run frantically across the pastures, kicking in a vain attempt to deter the flies. In both species the eggs are a narrowed oval shape, about $1 \mathrm{~mm}$ long, and smooth with a dull yellow color.

The eggs will hatch in 3-7 days, and the maggots will crawl to the base of the hairs on which they were attached and then penetrate the skin, using enzymes to break down skin tissues and enable them to get under the skin to the soft tissue. First instar maggots will then migrate through the animal, taking different routes depending on the species. The common cattle grub migrates through connective tissue to the mucous membrane of the esophagus, and the northern cattle grub moves along nerve pathways to the spinal column. At this point the maggots are about $15 \mathrm{~mm}$ long.

In Florida, both species of grubs leave their resting sites and begin to migrate to the animal's back, arriving by early fall (October to November). When they arrive at the back, the maggots use their skin digesting enzymes again, this time to cut a breathing hole in the skin, which is known as the "warble pore." Once established, the maggots then molt to the second stage, and the host cow produces a 3-cm-wide boil called a "warble" around the maggot within 3-4 days. The maggots remain in the warbles for 1-2 months, growing and feeding on pus, dead cells, and other secretions before molting a final time to the third stage.

The mature grub (Fig. 5) is black and $30 \mathrm{~mm}$ long. It exits the warble through the breathing hole and drops off the animal onto the ground, where it pupates within 2-3 days. The pupal stage lasts for 1-3 months depending on temperature. When the adult warble flies emerge in the spring of the following year, they live for just 3-5 days. Adult flies lack functional mouthparts and do not feed, so their lives are short. They must quickly find a mate and lay their eggs. Warble flies mate within 24 hours of emerging from the pupa, and the females are ready to lay eggs within 20 minutes of mating. 


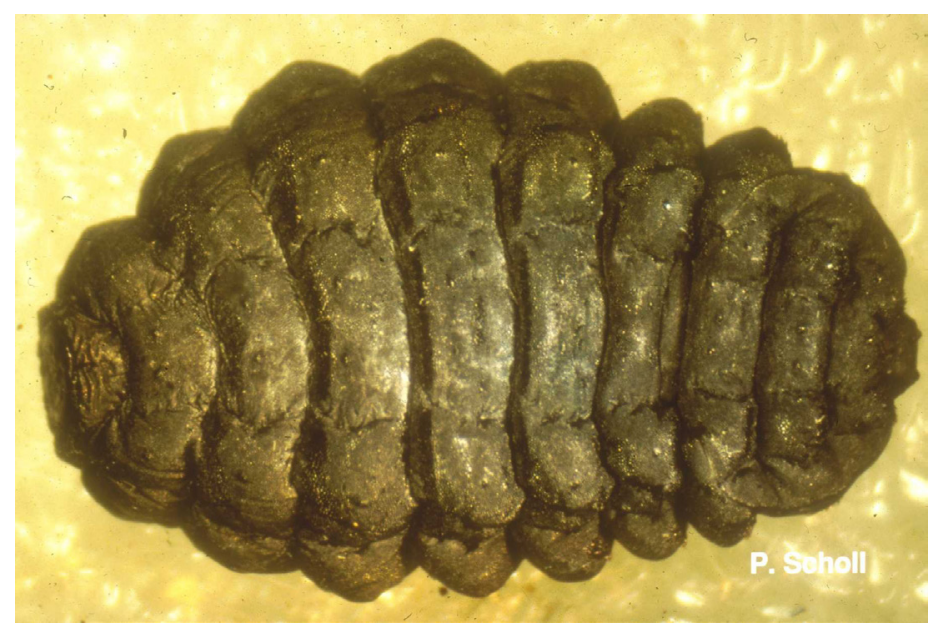

Figure 5. Mature third instar cattle grub. Credits: P. Scholl, USDA/Ag. Canada.

\section{Cattle Grub Damage}

Cattle grub infestations cause damage both directly and indirectly, and the effects are caused by both the adult warble flies and the immature cattle grubs. The adult flies, particularly of the northern cattle grub, cause panic when they are flying near cattle. Cattle that are being bothered by warble flies will show unusual behavior such as gadding or running across the pastures (Fig. 6). The reduced time spent feeding and the exertion from these attempts results in decreased weight gain. In first-year heifers, cattle grub avoidance appears to result in breeding and, subsequently, calving asynchrony. Breeding asynchrony may occur because of increased effort being spent avoiding flies, resulting in the time that the heifers breed being spread out over the season. Consequently, calves are born over an extended period (asynchronously), which results in increased costs to the farmer. Indirect damage may result as well if panicked cattle fall or run into fences or other objects. In pregnant animals, gadding may cause spontaneous abortions.

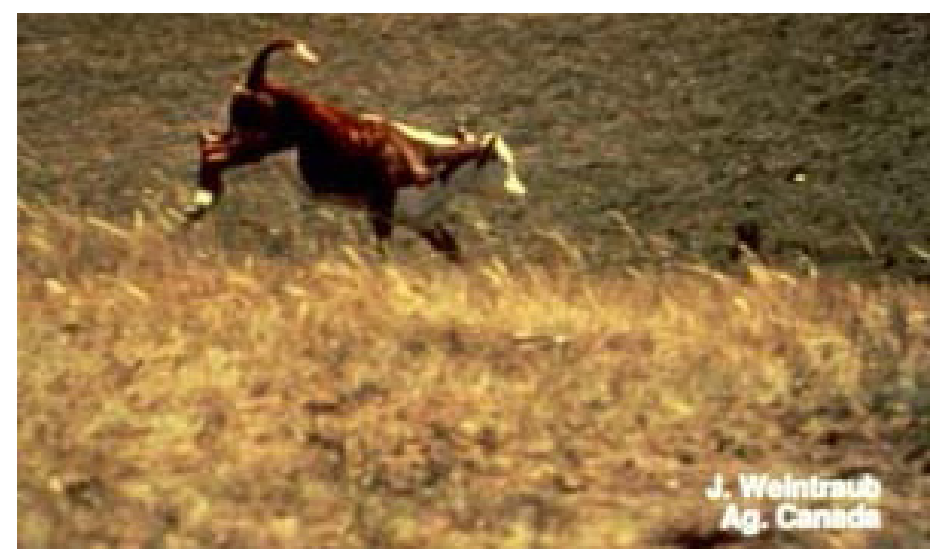

Figure 6. Cattle gadding in response to the presence of warble flies. Credits: J. Weintraub, Ag. Canada.
The cattle grubs also have a serious effect on cattle health and their value. There are four types of damage that may be caused by the immature stage.

\section{Adverse reactions in cattle due to killing of the maggots} too late in the season when they are passing through the esophagus (common cattle grub) or spinal cord (northern cattle grub). If an animal is infested with common cattle grubs during the esophageal migration period and the grubs are killed by the insecticide treatment, the esophagus will swell shut, and the animal will bloat, suffocate, and die. If an animal is infested with northern cattle grubs, the adverse reaction will present as a paralysis wherein the animal, unable to use its posterior limbs, will collapse partially and sit on the ground as a dog would. Often the animal will recover from the paralysis.

2. Reduced meat quality in the back area due to the presence of grubs at the time of slaughter. The tissue around the warbles will be green or yellow and jelly-like, and will need to be excessively trimmed.

3. Reduced hide value due to the holes that the maggots make in the skin for breathing (Fig. 7).

4. Low immunity due to the presence of the maggots; increased chance of contracting diseases and secondary infection of the warbles and other wounds.

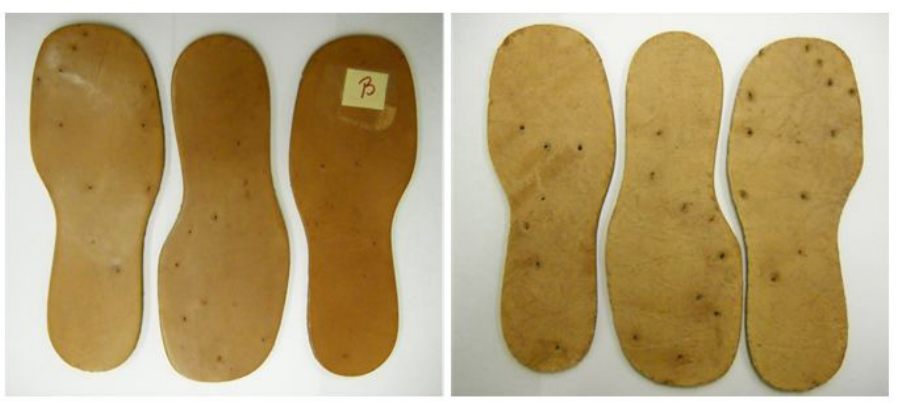

Figure 7. Example of cattle grub damage to hide. Credits: E. N. I. Weeks, University of Florida.

Cattle grubs also can affect other animals, most commonly humans and horses, as accidental hosts. In humans the maggots cause a condition called cutaneous larval migrans, in which after the maggots penetrate the skin they wander, causing visible red tracks that are very itchy. Human infestation with the northern cattle grub, in particular, may cause more adverse side effects if the maggots penetrate deeper. In horses the maggots migrate through to the animal's back where they cause abscesses and prevent riding because of the discomfort caused by the tissue damage. 
The economic impact of cattle grubs is due mainly to hide damage, decreased weight gain and reduced milk production. The hide can be worth up to $10 \%$ of the carcass value, and a grub-damaged hide is decreased greatly in value because of the grub's breathing holes. Decreases in milk yield due to the presence and infestation with cattle grubs are estimated at $10-30 \%$ of the normal yield. In the 1980 s the economic loss due to cattle grubs in North America was estimated to be $\$ 600$ million per year.

\section{Monitoring}

In areas where warble flies are common, it is important to monitor cattle and other livestock for signs of warble fly activity and cattle grub infestation to enable informed decisions about cattle grub control. Unusual behavior such as gadding indicates warble fly activity and likely presence of the northern cattle grub in the area. Monitoring of livestock for the presence of warble fly eggs includes examination of the lower regions (legs and belly), particularly with animals younger than five years. The development of immunity results in lower survival of maggots in older animals, so the youngest animals are most at risk of warble development.

Later in the season, cattle can be examined for the presence of warbles. Run a hand down the backline, and feel for cystlike bumps. If the hair around the warble is parted, then the breathing hole may be visible. As with monitoring for eggs, prioritize the examination of animals less than five years of age because they are the most likely to be infested. In some countries, cattle grub prevalence is monitored through analysis of blood or milk using immunodiagnostic tests. Monitoring enables farmers to make informed decisions about the best time to treat cattle and the most effective treatment methods to use. For example, if eggs are present, farmers may treat with a topical insecticide once the warble flies are dead but before the eggs hatch. Alternatively, farmers may also choose to use a systemic insecticide to kill immature grubs throughout the summer but before the treatment cut-off. If warbles are found later in the year, then the farmer may opt for mechanical removal to reduce damage to the hide and carcass.

\section{Control}

\section{Mechanical Removal}

Mature cattle grubs can be squeezed out of the warble through the breathing hole (Fig. 8). Removal of immature grubs is more difficult because of their backward spines. Take care to avoid rupturing the grub during extraction because exposing the cow to the internal body fluids of the grub may produce localized inflammations, abscesses, or anaphylactic reactions in previously exposed animals.

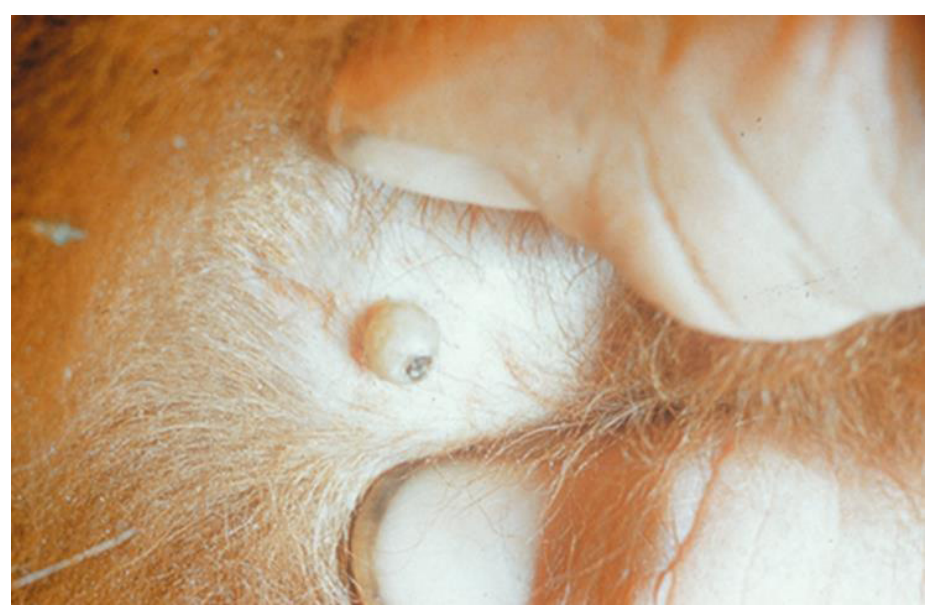

Figure 8. Mechanical removal of cattle grub.

Credits: P. E. Kaufman, University of Florida.

\section{Chemical Treatment}

Many different insecticide application methods are labeled for cattle grub control, including injections, sprays, dips, pour-ons, and spot-ons. The best results have been observed with targeted pour-on and spot-on applications. These products also can provide control of multiple livestock pests. If timed well during the season, one insecticide application could control for cattle grubs, horn flies, ticks, and lice.

Systemic insecticides are the primary tool for management of cattle grubs on livestock facilities, both beef and non-lactating dairy cattle farms. Systemic treatments can be used early in the season to kill the maggots migrating through the tissue, and some also may be used later in the season to kill the grubs in the warbles, although this is not recommended.

Most insecticides must not be used for a designated period before an animal is slaughtered in order to ensure that the meat is free of pesticide residues. There is only one systemic insecticide that is permitted for use with lactating dairy cattle.

When treating cattle with systemic insecticides for cattle grub control, it is important to consider the life cycle of the insect and time the treatment accordingly. The safest time to kill the maggots is from egg hatch in spring until just before the migrating maggots reach the sites in the cow's esophagus, for the common cattle grub, or spinal cord, for the northern cattle grub. If the treatments are applied too late, the maggots will be killed in the resting sites, where they will prevent normal body functions and cause severe 
side effects (see type 1 of the 4 damage types described in the subsection, Cattle Grub Damage, above). To protect cattle against these adverse side effects, the state of Florida's treatment cut-off date is August 31. Treatment after this date is dangerous and may kill your cattle. Treatments applied in the month of August are safe and should provide effective control of the cattle grub.

\section{TOXIC REACTIONS}

Chemical treatments for cattle grubs can cause toxic reactions if they are given too late in the cattle grub season or if the dose is too high. There are three problems that may cause side effects in cattle treated for cattle grubs:

\section{Treatment applied too late. Maggots killed in "at risk"} sites in esophagus or spinal cord will cause serious side effects. Side effects from late treatment are potentially lethal in common cattle grub infestations.

\section{Treatment applied at too high a dose. Overdoses of} chemical treatments for cattle grubs have caused pesticide toxicity in cattle.

\section{Unsuccessful grub removal. Grubs ruptured during} removal from the warble may result in an anaphylactic reaction in sensitized animals.

If treatment is applied too late in the season and maggots are killed in the resting sites, then serious side effects will occur (Fig. 9). Maggots of the common cattle grub dying in the esophagus will cause difficulty breathing, salivation, vomiting, and potentially death through suffocation. Northern cattle grub maggots dying in the spinal cord will cause temporary posterior paralysis and weakening of the back legs, although affected animals will usually recover. To prevent toxic reactions due to poor timing of insecticide applications, apply systemic insecticides for cattle grubs before the cut-off date of August 31(in Florida). In areas where animals may be infested with cattle grubs, this date also should be taken into consideration when applying insecticides as a control measure for other livestock pests.

High doses of insecticide may result in pesticide toxicity in treated animals. Appropriate doses should always be calculated by following the label directions and applying the correct dose to each animal. If overdosing occurs, the symptoms of pesticide toxicity include stringy saliva, diarrhea, weak back legs and abdominal cramps.

Grubs that die or are ruptured during mechanical removal produce an intense allergic reaction in sensitized animals due to the presence of the insect's body fluids. Older animals are more likely to have previous exposure to cattle grub body fluids than young animals and calves and, therefore, they have increased risk of anaphylactic shock. Take special care when treating older animals and be particularly careful with pregnant animals as well: spontaneous abortions because of reactions to ruptured cattle grubs have been reported.

Animals that are under stress or sick should not be treated with systemic insecticides. Remember that only certain insecticides can be used on lactating dairy cattle, and most insecticides must be withdrawn within a set period before slaughter to protect the meat from contamination with insecticide residue.

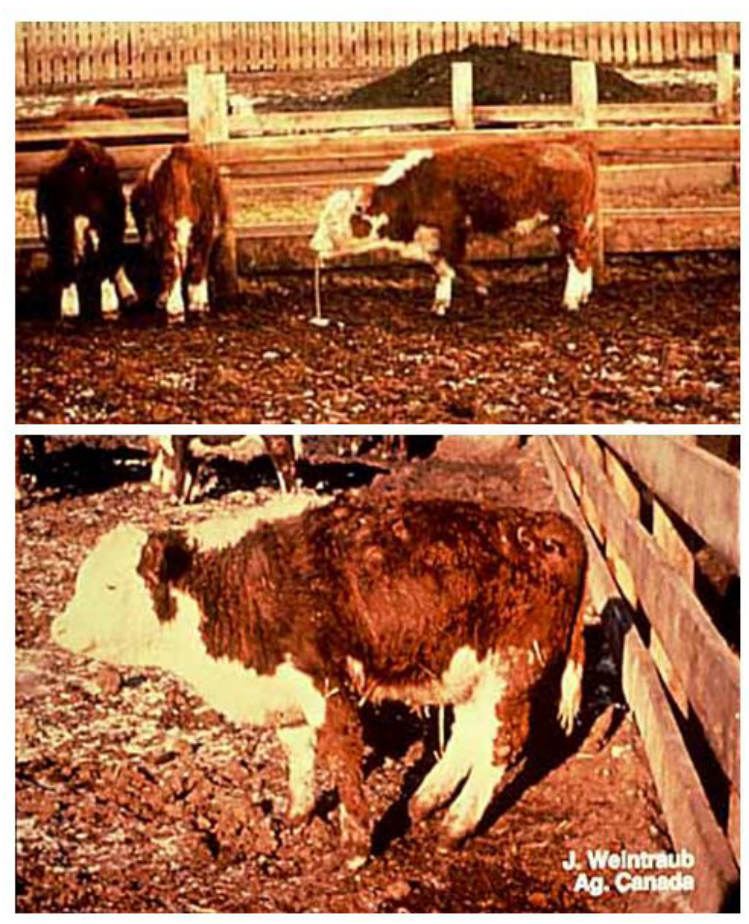

Figure 9. Treatment reactions. Vomiting due to common cattle grub larvae in the esophagus (top), and hindquarter paralysis due to northern cattle grub in the spinal cord (below).

Credits: J. Weintraub, Ag. Canada. 


\section{Selected References}

Drummond, R. O., G. Lambert, H. E. Smalley, and C. E. Terrill. 1981. Estimated losses of livestock to pests, pp 111-127. In D. Pimentel (ed.), CRC Handbook of Pest Management in Agriculture, Vol. 1. CRC Press Inc., Boca Raton, Florida, USA.

Drummond, R. O. 1984. Control of larvae of the common cattle grub (Diptera: Oestridae) with animal systemic insecticides. J. Econ. Entomol. 77: 402-406.

Drummond, R. O., J. E. George, and S. E. Kunz. 1988. Control of arthropod pests of livestock: a review of technology. CRC Press, Boca Raton, Florida.

Glick, J. I. 1976. Infestation of native Florida cattle with the northern cattle grub, Hypoderma bovis (Diptera: Oestridae). Fla. Entomol. 59: 190.

Hassan, M., M. N. Khan, M. Abubakar, H. M. Waheed, Z. Iqbal, and M. Hussain. 2010. Bovine hypodermosis - a global perspective. Trop. Anim. Health Prod. 42: 1615-1625.

Holste, J. E., D. D. Colwell, R. Kumar, J. E. Lloyd, N. P. M. Pinkall, M. A. Sierra, J. W. Waggoner, W. K. Langholff, R. A. Barrick, and J. S. Eagleson. 1998. Efficacy of eprinomectin against Hypoderma spp. in cattle. Am. J. Ver. Res. 59: 56-58.

Pruett, J. H., and S. E. Kunz. 1996. Development of resistance to Hypoderma lineatum (Diptera: Oestridae) within a cattle herd. J. Med. Entomol. 33: 49-52.

Scholl, P. J., R. Hironaka, and J. Weintraub. 1988. Impact of cattle grub (Hypoderma spp.) (Diptera: Oestridae) infestations on performance of beef cattle. J. Econ. Entomol. 81: 246-250.

Scholl P. J., and J. Weintraub. 1988. Gonotrophic development in Hypoderma lineatum and H. bovis (Diptera: Oestridae), with notes on reproductive capacity. Ann. Entomol. Soc. Am. 81: 318-324.

Scholl, P. J. 1993. Biology and control of cattle grubs. Annu. Rev. Entomol. 39: 53-70.

Scholl, P., E. P. Catts, and G. R. Mullen. 2009. Myiasis (Muscoidea, Oestroidea), pp. 309-336. In G. R. Mullen and L. A. Durden (eds.), Medical and Veterinary Entomology, 2nd ed. Elsevier Science, San Diego, CA. 